\title{
Technology and Education: an Ever-Growing Intersection
}

\author{
G. Vincenti* and J. Braman
}

Towson University, Towson, MD, USA

Received on 12 July 2012; published on 10 August 2012

Copyright (C) 2011 Vincenti and Braman, licensed to ICST. This is an open access article distributed under the terms of the Creative Commons Attribution licence (http://creativecommons.org/licenses/by/3.0/), which permits unlimited use, distribution and reproduction in any medium so long as the original work is properly cited.

doi: 10.4108/eeel.2012.07-09.e1

\section{Technology continues to push forward}

Taking with it many facets of everyday interaction, including that of teaching and learning. As the educational forefront is continually advancing through the introduction of new ideas, technologies and media, it is important to report all of these changes in order to stay abreast of its impacts. It is with great pleasure that we introduce our second issue of the ICST Transactions on eEducation and e-Learning.

It has always been our belief that it is important for educators to experiment with new instructional tools and pedagogical approaches in order to find innovative ways to enhance teaching and learning. It is through the expertise of many educational pioneers that we are able to gain invaluable insight into new methods of teaching. Education should change and adapt as both society and technology evolve.

Even though technology can be a great asset to educators, technology alone does not guarantee learning. Students must be engaged and encouraged to apply their skills and understanding in order to retain and process new information. Many of today's students are comfortable using technology, especially the digital natives (Prensky, 2001). The idea of technology in the classroom is now a prerequisite rather than an index of innovation. Educators must have an understanding of the technology they are using in order to choose the appropriate tool and to implement it the most practical way for their classroom. As the very nature of the classroom has evolved into a new learning space, new creative approaches are needed to solve today's educational problems. Some argue that challenges stem from issues like teacher attrition, lack of parental

*Corresponding author. Email: giovanni.vincenti@icst.org involvement and student's reading abilities, which all hinder progress in education (Boyer \& Hamil, 2008). Others note challenges related to inequality and cultural differences as creating additional learning barriers and complexities (Banks \& Banks, 2009). Whatever the issue, there are many unique solutions and innovations that can help educators alleviate many problems through technologies. Teachers of all disciplines need to stay current and up-to-date with the ever changing arena of learning and educational technologies. Though a difficult and daunting task, it is through publications such as this one that we hope to make the journey a little easier, as we can learn from the experiences and many experiments conducted in the field of the "classroom".

There is a growing need to investigate further the impact of potential e-learning tools and other collaborative social Web 2.0 technologies for online and hybrid teaching (Solomon \& Schrum, 2010). Many new tools have become available in the last several years, allowing for many creative teaching moments and learning endeavors. For instance the use of augmented reality coupled with mobile and tablet based learning (Tarng \& Ou, 2012). The availability of cell phones and other mobile devices had open many new doors, allowing for many types of learning. Many forms of interactive simulations can be conducted in virtual labs and in 3D environments and even social virtual worlds. We have been experimented in such domains for the past several years, pushing the envelope and encouraging others to experiment in new mediums to further engage students (Vincenti \& Braman, 2011). The society of tomorrow will be very different and full of many new challenges. Teaching our students better today will prepare them for the road ahead.

This issue is composed of a fair representation of current trends in technology-based solutions for education. Ranging from gaming and virtual worlds to 
mobile applications, our authors discuss in detail their ideas, findings and roadmaps regarding the fast-paced niche on which this journal focuses. Many of these articles present cutting edge research combined with many years of proven pedagogy.

Nick Flor opens this issue with the article titled "A method for teaching the modeling of manikins suitable for third-person 3-D virtual worlds and games". This work focuses on the effectiveness of virtual worlds and gaming towards formal and informal education by addressing the lag that the 3-dimensional representation of avatars suffers when compared to the realism of immersive virtual environments. Through the process described in this work the reader will gain a greater understanding of how to design quick prototypes that will complement successfully any high quality educational material offered through 3-dimensional environments. This work goes beyond the simple narration of what was done by also including an easy to follow appendix that takes the reader through a step-wise journey to implementing better virtual manikins.

In the second article titled "Animating instructional materials in computer education: an approach to designing and teaching concepts in data structures using LATEX", Osikoya and Oluwalani approach the topic of creating successful visualizations of complex processes through simple 2-dimensional technologies. In particular, this work illustrates the process of creating animations describing stacks, queues and trees by composing sequential images then supported by vocal narrations describing the material displayed. The strength of this article is easily found in the recipe approach that the authors give to creating the visualizations, by including LATEX code that the reader can use as a platform to construct more complex visualizations or simply to learn how to use this free technology.

Fleischer, Bredl and Weise then shine a spotlight on collaboration through the third article in this issue, titled "Collaboration on the web - Chances of participation in a formal education context". This work addresses the often complex dynamics of collaborating through the internet pointing the efforts in the direction of managing the adoption of digital media in an academic setting. This case study offers precious recounts of their experience, offering a significant look into the collaborative process that the reader can apply in multiple ways in the classroom or in the organization of academic activities.

The fourth article, "Scaffolding in mobile science enquiry-based learning using ontologies" by Ahmed, Parsons and Mentis, opens a window on the innovative use of mobile communications technologies in the classroom. As this topic is gaining significant momentum at all levels of society, the authors bridge theory and practice successfully through a deep understanding or mapping ontologies and the concepts they formalize to technical elements that eventually bring content to students. The reader will be able to follow the project from its most abstract notions all the way to the most practical aspects of implementation through this well- written contribution, then obtaining all the tools to extrapolate the basics and carry them to other subject domains.

Sankaranarayanan closes this issue by also focusing on smart phones and mobile computing in the article titled "Smart agent based mobile tutoring and querying system". In this contribution the author publishes the implementation of a previous pilot study that aims at constructing a tutoring system that any student may carry on their mobile device. Through this article the reader can gain a better understanding of the technical difficulties that are very often associated with the creation of smart agents, especially in an educational setting.

In closing, we hope that the cross-section of research offered through this issue will let you not only learn from the work of others, but will inspire you to incorporate some of these concepts into your own field of expertise and practice. We wish to invite you to consider publishing your own work through our ICST Transactions on eEducation and e-Learning, joining a pool of excellent researchers and practitioners who have collaborated with us. It is through the efforts of many that we can begin to understand the best ways to teach and learn through technology.

Giovanni Vincenti and James Braman Editors-in-Chief

\section{References}

BANKS, J. and BANKS, C. (2009) Multicultural Education: Issues and Perspectives, 7th ed. (Hoboken, NJ: Wiley).

BOYER, A. and HAMIL, B. (2008) Problems Facing American Education. Focus on Colleges, Universities, and Schools 2(1): 19.

PRENSKY, M. (2001) Digital Natives, Digital Immigrants. On the Horizon 9(5): 1-6.

SOLOMON, G. and SCHRUM, L. (2010) Web 2.0: How-To for Educators (Washington, DC: International Society for Technology in Education).

TARNG, W. and OU, K. (2012) A Study of Campus Butterfly Ecology Learning System Based on Augmented Reality and Mobile Learning. In Proceedings of the Seventh IEEE International Conference on Wireless, Mobile and Ubiquitous Technology in Education (WMUTE), Takamatsu, Kagawa, Japan, March 27-30, 2012 (Los Alamitos, CA: IEEE), 62-66.

VINCENTI, G. and BRAMAN, J. (2011) Teaching through Multi-User Virtual Environments: Applying Dynamic Elements to the Modern Classroom (Hershey, PA: IGI Global). 